Konrad P. Aguila, MD

Department of Otorhinolaryngology-Head \& Neck Surgery Jose R. Reyes Memorial Medical Center
Correspondence: Konrad P. Aguila, MD

Department of Otorhinolaryngology Head \& Neck Surgery

Jose R. Reyes Memorial Medical Center

Rizal Ave., Sta. Cruz, Manila 1003

Philippines

Telefax: (632) 743-6921

E-mail:kon_eagle@yahoo.com

Reprints will not be available from the author.

No funding support was received for this study. The author signed a disclosure that he has no proprietary or financial interest with any organization that may have a direct interest in the subject matter of this manuscript, or in any product cited in this report.

Presented at the Surgical Innovation Contest (1st Place) Philippine Society of Otolaryngology Head \& Neck Surgery Annual Convention, Westin Philippine Plaza Hotel, Pasay City, December 1, 2005.

\section{Self-Retaining Harpoon Tympanostonomy Tube with Applicator}

\begin{abstract}
Objective: To describe a novel harpoon design for a low cost, self retaining tympanostomy tube with applicator used in a 38-year-old female for otitis media with effusion.

\section{Methods:}

a. Study design: Instrumental Innovation/Case Report

b. Setting: Tertiary Hospital in Metro Manila

Results: The tympanostomy tube was inserted under endoscopic guidance within 10 seconds, remained in place for two months with relief of symptoms, and spontaneously extruded by the seventh month of follow-up.

Conclusion: The harpoon-designed tube with applicator provided ease of insertion and good anchorage in the tympanic membrane. Maximizing the use of a stylet-needle as both perforator and applicator simplified the tympanostomy and ventilating tube insertion procedures into a single maneuver.
\end{abstract}

Key words: middle ear ventilation, tympanostomy tube insertion, grommet insertion, instrumentation

THE PATHOGENESIS and natural history of middle ear disease were most strikingly altered with the reintroduction of practical, safe and effective middle ear pressure equalization tube (PET) by Armstrong in 1954'. Otitis Media with effusion (OME) is a common sequel of acute otitis media (AOM). Otalgia, aural fullness and hearing loss are the common complaints.

Oral antibiotics remain the treatment of choice for acute otitis media. Over $90 \%$ of patients are clinically cured two weeks after the onset of therapy ${ }^{2,3}$. Acute symptomatic failures are observed, in part due to antibiotic resistance, increasing tympanocentesis recommendations for culture purposes in $\mathrm{AOM}^{4}$. For persistent effusion, the most commonly used treatment option for most patients is tube insertion ${ }^{5}$. Myringotomy without tube insertion is not commonly recommended because of rapid closure of the tympanic membrane fenestration ${ }^{4}$. Myringotomy with placement of ventilating tubes has become the standard of care for children with OME that has lasted more than three to four months and is unresponsive to conservative treatment ${ }^{6}$. Tympanostomy tubes are highly effective for children and adults with middle ear effusion, with most remaining free of middle ear disease while the tubes remain patent and functional'. Prolonged middle ear ventilation of approximately 6 to 12 months provided by most first line PETs helps to restore the Eustachian tube- middle ear-mastoid complex to a more normal physiologic state, improving hearing and preventing infection ${ }^{8}$.

Because of prohibitive costs and inavailability of commercial tympanostomy tubes, it is common practice in our institution to fabricate myringotomy tubes from 18-gauge intravenous plastic catheters cut into $5 \mathrm{~mm}$ segments and heat-flanged over both ends. We describe a novel low-cost, self retaining harpoon tube with applicator that facilitates both tympanostomy and insertion into, as well as anchorage and retention in, the tympanic membrane.

Philipp J Otolaryngol Head Neck Surg 2007; 22 (1,2): 27-30

CPhilippine Society of Otolaryngology - Head and Neck Surgery, Inc 
Table 1. Tympanostomy Tubes Manufactured by Medtronic Xomed, USA locally distributed by FAMED Company

\begin{tabular}{|lcc|}
\multicolumn{1}{c}{ Type } & Price per box(5pcs) & Price per piece \\
\hline Sheehy Collar Button & Php 5,610 & Php 1,122 \\
Shepard Grommet & Php 3,300 & Php 660 \\
Pediatric & Php 3,630 & Php 726 \\
Goode T-tube & Php 6,930 & Php 1,386 \\
\hline
\end{tabular}

To compute for the total cost in the production of one set of the device, the cost of one piece of IV catheter, one piece of tuberculin syringe and $1 / 4$ of the total amount in the fabrication of the tube were added giving a sum of Php57.25.

\section{Procedure:}

\section{A. Tympanostomy Tube Fabrication}

A $2 \times 1 \mathrm{~cm}$. piece of aluminum foil was rolled around the intravenous plastic catheter about $1 \mathrm{~mm}$ from its tip to serve as guide, with the stylet needle used as stopper. The rim edge was smoothened with a sharp blade (Figures $1 \& 2$ ). The rolled aluminum foil was slid further away to $2 \mathrm{~mm}$ from the catheter tip, and two slits $180^{\circ}$ apart were cut into both sides of the catheter, each starting from the edge of the guide aluminum foil and extending $1 \mathrm{~mm}$ towards the tip. The stylet prevented each cut from extending to the other side of the catheter (Figure 3). The flaps made on each proximal side of the catheter were then elevated and folded, and the distal side of the catheter was cut 5-7 $\mathrm{mm}$ from the tip, and the rim was flared over an open flame.

Alternately, two tongue depressors could be used as template, cutting a groove in both tongue depressors for the catheter to fit between them when placed together, exposing 2-3 $\mathrm{mm}$ of the tip to be flared. It could then be secured with a clip and heated over an open flame (Figure 4). The procedure was repeated to fashion four tubes (Figure 5).

\section{B. Tympanostomy Tube Applicator Set:}

A second 18 Gauge intravenous plastic catheter was marked alongside the fabricated tympanostomy tube and cut at a point from the tip corresponding to the tube length. The stylet was reinserted into the intravenous catheter, and the cut portion of the intravenous catheter and fabricated tympanostomy tube were reinserted into the stylet (Figure 6). After trimming excess portions of the intravenous catheter that could interfere with insertion (Figure 7), the assembly was attached to a tuberculin syringe to serve as handle (Figure 8) and soaked for 30 minutes in Glutharaldehide 2\% (Glutharex ${ }^{\mathrm{TM}} 3 \mathrm{M}$, Columbia) for sterilization then rinsed with sterile distilled $\mathrm{H} 20$.

Note that the tube's end was modified into a harpoon-like structure which was incorporated into the tip of an intravenous catheter system to become a self-retaining tympanostomy tube with applicator. Using the attached tuberculin syringe as a handle, the metal stylet of the intravenous catheter was designed to puncture the tympanic membrane and facilitate tube insertion in one motion. The arrow-

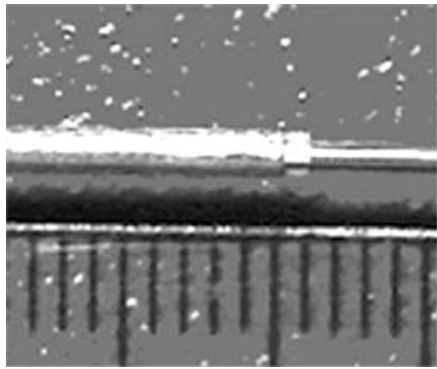

FIGURE 1:

Aluminum foil used a guide

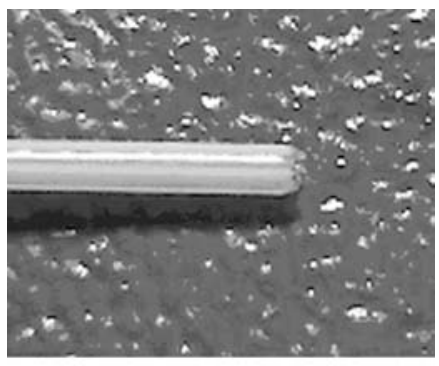

FIGURE 2:

Smoothened edge

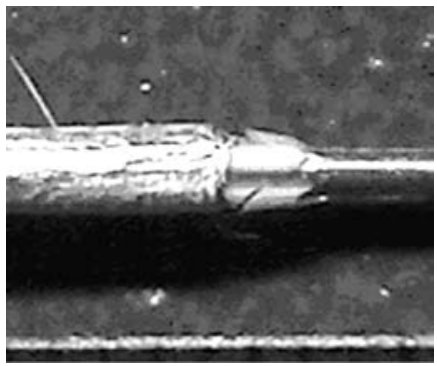

FIGURE 3:

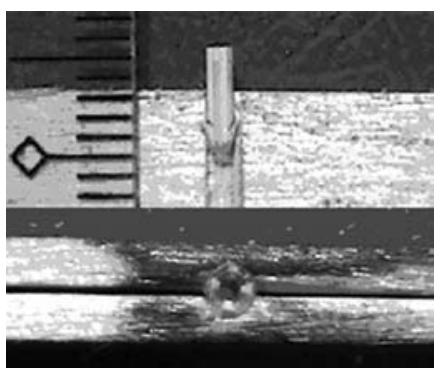

Make a slit $180^{\circ}$ apart

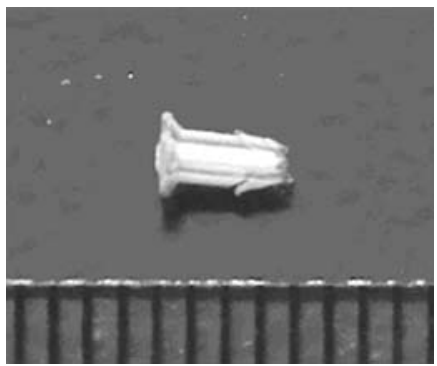

FIGURE 4:

Tongue depressors as template in burning one end to make a flare end

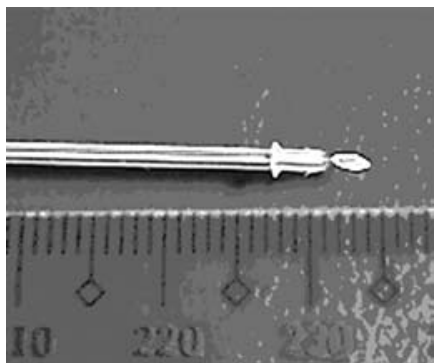

FIGURE 5 :

Finished product of a tympanostonomy tube 


\section{SURGICAL INNOVATIONS AND INSTRUMENTATION}

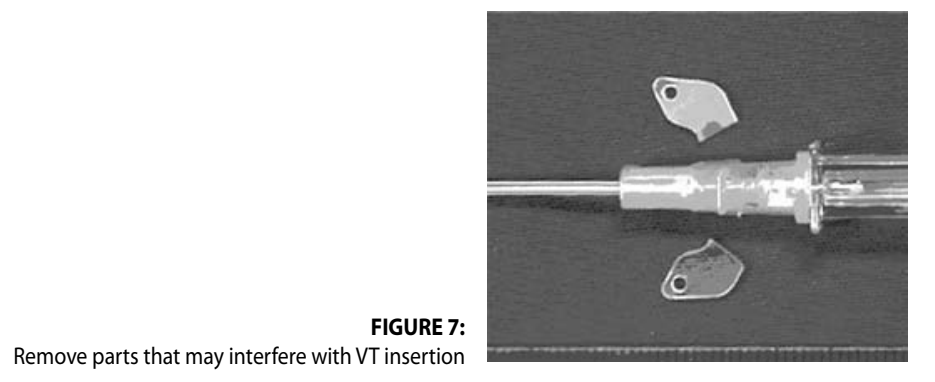

Remove parts that may interfere with VT insertion
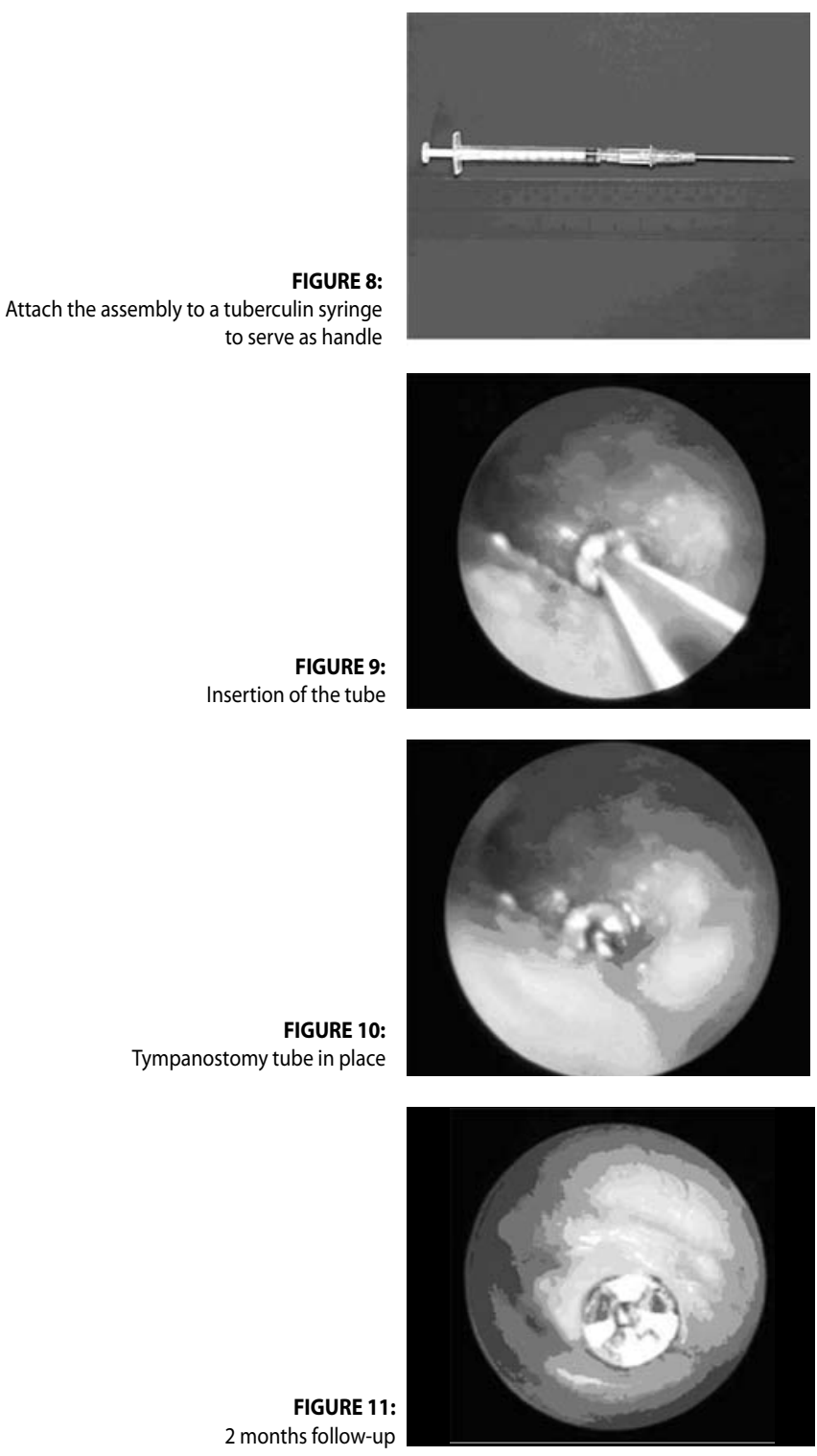

head design automatically leaves the tube in place after applicator withdrawal.

\section{RESULTS}

With institutional review board approval and informed consent, the device was used on a 38-year-old female with eight months' aural fullness and hearing loss unrelieved by medications diagnosed to have otitis media with effusion. Tympanostomy tube insertion was performed under topical anesthesia using Lidocaine $25 \mathrm{mg}$, Prilocaine $25 \mathrm{mg}$, 5\% cream (EMLA ${ }^{\text {TM }}$ AstraZeneca) applied for 15 minutes. A $2.7 \mathrm{~mm} \mathrm{O} 0^{\circ}$ rigid scope (model 8670.31 Wolf USA) and Telecam video system (SL NTSC, Karl Storz, Germany) were used to document the procedure (Figures 9\&10). The tube was applied within 10 seconds, obtaining clear serous fluid with relief of symptoms. The tube was in place at one week and two months follow-up (Figure 11), and spontaneously extruded by the seventh month follow-up.

\section{DISCUSSION}

There are many different types of tympanostomy tubes currently in use. They differ in size, shape, materials, coatings and theoretical advantages for the surgeon or patient. Commercially available tympanostomy tubes are expensive and burdensome to our financially constrained patients. The cost of a single tympanostomy tube obtained from local suppliers ranges from Php 500 to Php 1,500 depending on the type $\&$ brand (Table 1). The fabrication of this device will only cost Php 57.25.

In our local hospital setting, tympanostomy tubes were improvised using a gauge 18 intravenous catheter. One IV catheter was cut and reduced into four $10 \mathrm{~mm}$ long tubes with both ends of the tubes heated to make patent flared rims. The technique of myringotomy and ventilating tube insertion was the same as the standard procedure.

The new self retaining tympanostomy tube with applicator is designed to aid the surgeon in performing myringotomy and ventilating tube insertion in a single maneuver. This instrument was inspired by the principle of inserting a catheter intravenously with the aid of a stylet-needle that is subsequently withdrawn to leave the catheter in place. To keep the new tympanostomy tube in place, it is designed like a harpoon which facilitates smooth insertion but is kept automatically in place upon slight retraction with the aid of the hooks located on each side of the tube (Figures 12-14). The stylet-needle functions as perforator and applicator eliminating the need for a tympanostomy blade further reducing the expense for the procedure. The attached syringe not only serves as a convenient handle but is also very useful in aspirating discharge for specimen collection, hence, making myringotomy and tympanostomy tube insertion less time consuming.

The device can be used under local or general anesthesia. The tympanic membrane can be visualized with or without the use of an aural speculum, under otomicroscopic magnification, or videoendoscopic guidance. During the procedure, care should be given not to injure the external auditory canal or any other part of the tympanic membrane. The plastic IV catheter may be slid gently forward using the middle finger until the posterior flange end touches the tympanic 


\section{SURGICAL INNOVATIONS AND INSTRUMENTATION}

Philippine Journal Of Otolaryngology-Head And Neck Surgery $\quad$ Vol. 22 Nos. 1 \& 2 January -June; July - December 2007

PJOHLS

\section{MATERIALS AND METHODS}

\begin{tabular}{|c|c|c|c|}
\hline Material & Manufacturer & Amount & Cost (PhP) \\
\hline $\begin{array}{l}\text { INTRAVENOUS } \\
\text { CATHETER } 18 \\
\text { GAUGE, } 1.3 \times 45 \mathrm{~mm}\end{array}$ & $\begin{array}{l}\text { INTROCAN-W, } \\
\text { B.BRAUN Laboratories, } \\
\text { Brazil }\end{array}$ & 2 & 36.50 each \\
\hline $\begin{array}{l}\text { TUBERCULIN (1ml) } \\
\text { SYRINGE }\end{array}$ & $\begin{array}{l}\text { Becton, Dickinson \& Co. } \\
\text { Singapore }\end{array}$ & 1 & 6.50 each \\
\hline BLADE №. 11 & Feather, Safety Razor Co., LTD, Japan & 1 & 10.00 each \\
\hline CANDLE & $\begin{array}{l}\text { LIWANAG, Sevilla Candle Factory, } \\
\text { Malabon City, Philippines }\end{array}$ & 1 & 7.00 each \\
\hline $\begin{array}{l}\text { TONGUE DEPRESSOR } \\
\text { Depressor }\end{array}$ & $\begin{array}{l}\text { Union Wooden Tongue } \\
\text { Manufacturing Co. Philippines }\end{array}$ & 2 & 0.50 each \\
\hline ALUMINUM FOIL & Paramount Foil Manufacturing, U.S.A & $2 \mathrm{~cm} \times 1 \mathrm{~cm}$ & negligible \\
\hline
\end{tabular}

membrane. Special attention should be given to introduction of the device, inserting the tube until the hooks have penetrated the tympanic membrane and gently retracted until the hooks are secured. Avoid pushing the device way beyond the tympanic membrane into the middle ear cavity. Such an occurrence is a remote possibility owing to the relatively smaller puncture produced by the needle compared to the larger posterior flange of the device which functions as a stopper, but could potentially happen if extreme force is applied. The device should self-extrude, but removal may be performed with fine serrated end ear microforceps.

This modification in the fabrication of a tympanostomy tube from a gauge 18 IV catheter made tube application fast and easy. The harpoon design facilitated tube insertion into the tympanic membrane and helped keep the tube in place. Aside from the low cost of material in the production, maximizing the use of stylet-needle, functioning as perforator and applicator eliminated the need for a tympanostomy blade, which simplified the tympanostomy and ventilating tube insertion procedures. Although the device was used effectively and safely in one patient, evidence is lacking with regards extrusion rate, risks and complications and further studies of its use on a larger sample size with longer duration of follow-up and comparison with commercially available tympanostomy tubes are suggested.

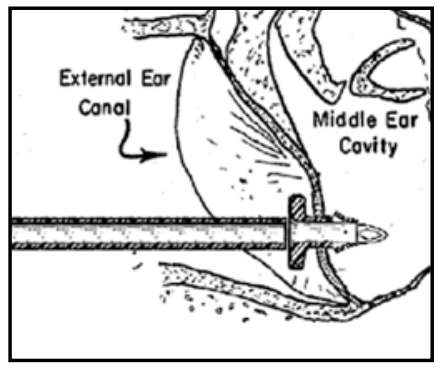

FIGURE 12:

Insertion of the device into the external auditory canal

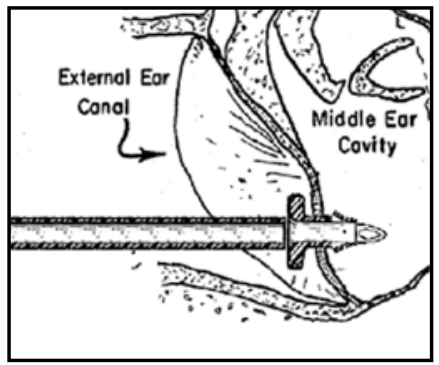

FIGURE 13:

Insertion of the device through the tympanic membrane

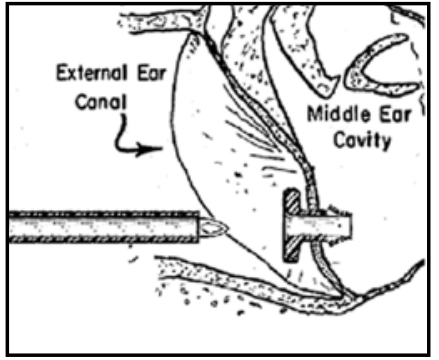

FIGURE 14

Withdrawal of the device leaving the tube in place

\section{ACKNOWLEDGEMENT:}

I would like to express my sincere gratitude to Jose A. Malanyaon, Jr., MD for his unselfish contribution in supervising the creation of this paper, and to the residents of the Department of ORL-HNS, JRRMMC for their untiring assistance in the documentation of the tympanostomy tube fabrication and performance of surgical procedure.

REFERENCES:

1. Armstrong BW. A new treatment for chronic secretory otitis media. Arch Otolaryngol 1954; 59:653-654.

2. McCracken $\mathrm{GH}$, Jr: Treatment of acute otitis media in an era of increasing microbial resistance. Pediatr Infect Dis J 1998; 17:1084-1089; discussion 580.

3. Rosenfeld RM, Verterees JE, Carr J, et al.: Clinical efficacy of antimicrobial drugs for acute otitis media: metaanalysis of 5400 children from thirty-three randomized trials. J pediatr 1994; 124:355-356

4. Pransky SM: Surgical strategies for otitis media. J Otolaryngol 1998; 27(Suppl 2):37-42.

5. Rosenfeld RM, Post JC; Meta-analysis of antibiotics for the treatment of otitis media with effusion. Otolaryngol Head Neck Surg 1992; 106:378-386.

6. Bower C, Waner,M. Laser Assisted myringotomy. Current Opinion in Otolaryngol Head \& Neck Surg $1999 \mathrm{Dec} ; 7(6): 335$

7. Mandel EM, Rockette HE, Bluestone CD, Paradise JL, Nozza, RJ. Efficacy of myringotomy with and without tympanostomy tubes for chronic otitis media with effusion. Arch Otolaryngo Head Neck Surg 1989; 115:1217-1224.

8. Brodsky L, Brookjauser P, Chait D, Reilly J, Duetsch E, Cook S, et al. Office-based insertion of pressure equalization tubes: The role of laser-assisted tympanic membrane fenestration. Laryngoscope, 1999 Dec 109(12) 2009-2014.

9. Lindstorm R, Reuben, B, Jacobson K, Flanary V, Kerschner J. Long-Term Results of Armstrong Beveled Grommet Tympanostomy Tubes in Children. Laryngoscope 2004 Mar; 114(3): 490-494. 